\title{
The Navigator's Aspect of PNC before and after ECDIS Implementation: Facts and Potential Implications towards Navigation Safety Improvement
}

\author{
Maro Car ${ }^{1}$, David Brčić ${ }^{2} * *$, Srđan Žuškin ${ }^{2}(1)$ and Boris Svilicic ${ }^{2}$ \\ 1 Nautical Department, University of Dubrovnik, Ćira Carića 4, 20000 Dubrovnik, Croatia; mcar1@unidu.hr \\ 2 Faculty of Maritime Studies, University of Rijeka, Studentska ulica 2, 51000 Rijeka, Croatia; \\ szuskin@pfri.hr (S.Ž.); svilicic@pfri.hr (B.S.) \\ * Correspondence: brcic@pfri.hr; Tel.: +385-98-633-538
}

Received: 1 October 2020; Accepted: 22 October 2020; Published: 26 October 2020

\begin{abstract}
The global maritime digitalization reflects on navigation and paperless vessels with Paper Navigational Charts (PNC) nowadays superseded by Electronic Chart Display and Information System (ECDIS). Considering the system implementation and its acceptance as a sole navigational means, opinions of navigators differ. Although the ECDIS mandatory implementation ended in 2018, some navigators have been still favouring PNCs, pointing out their advantages over ECDIS navigation. These standpoints may have an impact on the safety of navigation in terms of acceptance, interpretation, and understanding of the system as well as on conflict of standpoints of decisive navigational ranks, the latter reason being found as one of the real problems. The presented study has focused on a specific period, soon after the transitional period completion, aiming to determine the views of traditional navigation advocates, their arguments in the present maritime navigation paperless era and to identify potential problems emerging from the conflict of two navigational means. The research has induced two independent, internationally distributed questionnaires, dedicated to navigational ranks. The first survey has referred to the period from 2012 to 2018, marking the transition to ECDIS navigation. The second survey was conducted after the implementation period completion date. The answers were analysed and discussed from the navigational ranks' perspective, considering their competitiveness and the level of ECDIS education. The research results have indicated and confirmed that PNCs could not entirely be ruled out, at least at this stage. Besides definitive questionnaire answers, the findings have been supported with categorised comments as interpreted from the first survey questionnaire results. The paper aims to present the future of the PNCs, including possibilities of fusion with modern means. The proposed suggestions have been directed towards the benefits of maritime navigation safety, referring especially to disagreement between navigational ranks in terms of particular means acceptance.
\end{abstract}

Keywords: maritime navigation; electronic chart display and information system; paper navigational charts; electronic navigational charts; ECDIS EHO

\section{Introduction}

Acceptance of new technology is simply a generation problem, and it is only fairly related to navigational safety. - Unknown reviewer

The tangible development of the electronic chart systems started almost four decades ago. In the 1980s, International Hydrographic Organization (IHO) created a digital data exchange committee that laid down the foundation of the future electronic chart systems, thus enabling the beginning of a long process of PNC digitisation. One of the essential dates was 1st of July 2012, marking the beginning of 
the transitional period and the time when the ECDIS system was officially recognized as a system that meets chart carriage requirements. The transitional period lasted for six consecutive years, after which it became a mandatory navigational aid for most International Convention for the Safety of Life at Sea (SOLAS) vessels [1].

In the wake of global maritime digitalisation, traditional navigational means and the role of PNCs still appear to occupy an inevitable role. Besides recognised system- and data-centred ECDIS issues, the reasons for retaining PNCs include the feedback of navigators as central system stakeholders. The standpoints and views differ depending on experience, rank, and navigator's engagement with the system. To determine viewpoints and the way modern navigators perceive PNCs in the paperless era, the authors conducted two independent segments of research. The first survey was conducted in the period from the year 2014 to 1st of July 2018, the date of the completion of the transitional period for most SOLAS vessels. A second research was conducted after this date in the same year. Both researches were internationally distributed among the eligible maritime navigational ranks. The answers were analysed, summarized, and subsequently presented. Both expected and debatable findings emerged from the research. The latter, together with the provided observations, represented the motivation for further activities.

This paper is structured as follows. After the brief introduction on the topic, general features on paper and Electronic Navigational Charts (ENCs) have been presented, with an emphasis on the possible future outcomes of PNCs. Previously related research achievements are summarized, both on the research topic and the system in general. In the methodology chapter, the utilized system of research methods has been described. Research results have been presented subsequently and discussed in the following section. Based on previous findings and current research results, a rudimentary safety-related model has been defined, providing insight into potential system-related threats and possible risks which can be still considered to work in favour of traditional means. The paper concludes with summarized findings and desired future research.

\section{Background and Previous Research}

The SOLAS Convention requires installation of one ECDIS system on board vessels engaged in international voyages, other than non-tanker cargo ships with a gross tonnage of less than 10,000 built before 1st of July 2013. [1]. As a back-up arrangement imposed by carriage requirements, the following means have been recognized: (i) an Appropriate folio of PNCs (APC); (ii) autonomous system equipped with an independent emergency power supply; and iii) chart Radar [2-4].

The advantages of ECDIS navigation over traditional means can be summarized as workload reduction; task automation; and, as stated by the International Maritime Organization [5], the system usage contributing to the safety of navigation, particularly referring to predefinition and settings of safety parameters. Contrary to benefits, the system has been considered as a nonautonomous, still dependent on external factors such as sensors and hydrographic data, and prone to failures, malfunctions, and inability of proper performance nevertheless the root cause. The proper education and the lack of knowledge have been further recognised as drawbacks. This current-state pros and cons outcome, together with the desired path towards navigational safety have been the motivation for the research and for the results obtained and presented in continuation.

For ECDIS to be accepted as a system which meets charts carriage requirements, the following conditions have to be met: (i) the system has to be type-approved. (ii) it is necessary to employ up-to-date ENCs; (iii) the system software has to be maintained and compatible with the latest IHO standards; and, (iv) the system needs to have adequate and independent back-up arrangements [3,5-9].

During the ECDIS transitional period, several issues regarding the system have been recognized [10], although the current scientific collection of findings has been relatively scarce. The analyses of ECDIS-related accidents have emphasized the need for a more efficient system operation [11,12].

The previously conducted surveys and research results on justification of the system have indicated potential problems on different levels, generally related to the system, installation, maintenance, 
positioning, handling, navigation, insufficient operator's knowledge, ENCs production, displayed chart symbols without their features, etc. [10,13-15].

The summarized problems and difficulties (Figure 1) [13] have served as a further step towards the research. An overview of the existing ECDIS-related training has suggested some potential improvements in the training for deck officers, as well as in the increase of operational awareness [16-18].

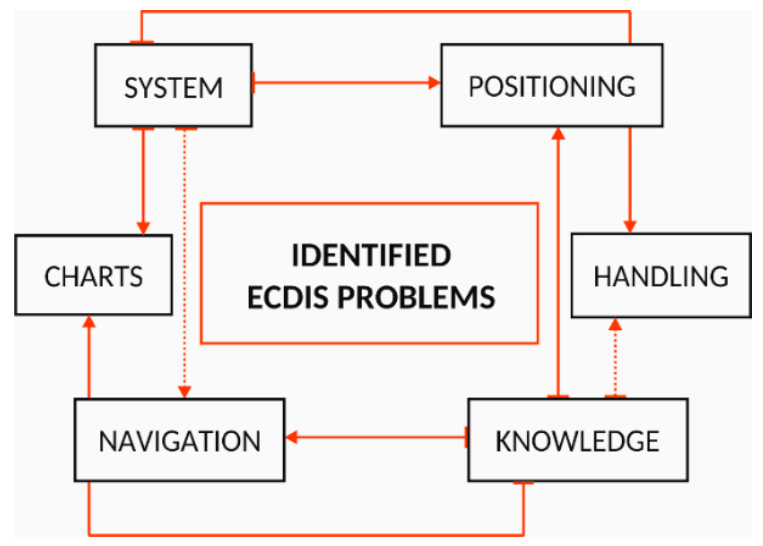

Figure 1. Summarized Electronic Chart Display and Information System (ECDIS)-related issues adapted and modified from [13].

There is no evidence that the system will be better accepted if system operators are more experienced seafarers [19]. Considering the particular navigational rank engagement and interaction with the system, a continuous need to adopt ECDIS Education and Training (EET) for an individual rank has appeared. The risks of overreliance, lack of situational awareness, and other subtle problems should not be disregarded $[13,15,20]$.

The navigator has to be aware of the system limitations and should always cross-check displayed information on the ECDIS with available and suitable sources [21] due to the risk that the safety of navigation is compromised by infrequently utilizing basic safety settings [22,23]. Furthermore, lack of standardization of the system settings, display, functions, and terminology among system manufacturers has showed a negative impact on the safety of navigation [24]. In Figure 2, a share of answers [20] referring to opinions on advantages of both navigational means has been presented, with the justification of opinions related to the main features.

To prepare for the future of PNCs, some critical issues on the subject have been introduced to the IHO and hydrographic offices [25]. The National Oceanographic and Atmospheric Association (NOAA) has already announced the end of the production of traditional PNCs and of the implementation of an online application, which will provide the users with an option to create their own, custom made charts [26].

Hydrographic offices have been considering whether to reduce or altogether discontinue the printing of the PNCs. As a consequence, even for ECDIS back-up arrangements, the world will not be covered entirely with PNCs. Concerning the ENCs world coverage and their features [27], the quality of the ENC data, in particular the depth hydrographic information, may vary, given that the source of surveys is mostly the same as on PNCs. There are approximately $75 \%$ of the navigable waters covered with ENCs where seafarers need to exercise caution or a high degree of caution due to the possible existence of uncharted dangers for navigation $[25,28,29]$. Recent efforts to provide a valuable voyage-planning tool for the vessels operating in the Arctic waters [29] has highlighted the importance of a proper ENC coverage, especially in the remote areas.

Inevitable reduction in the PNCs' production and the mandatory transfer to electronic means have been further problem-addressing points of the research. 


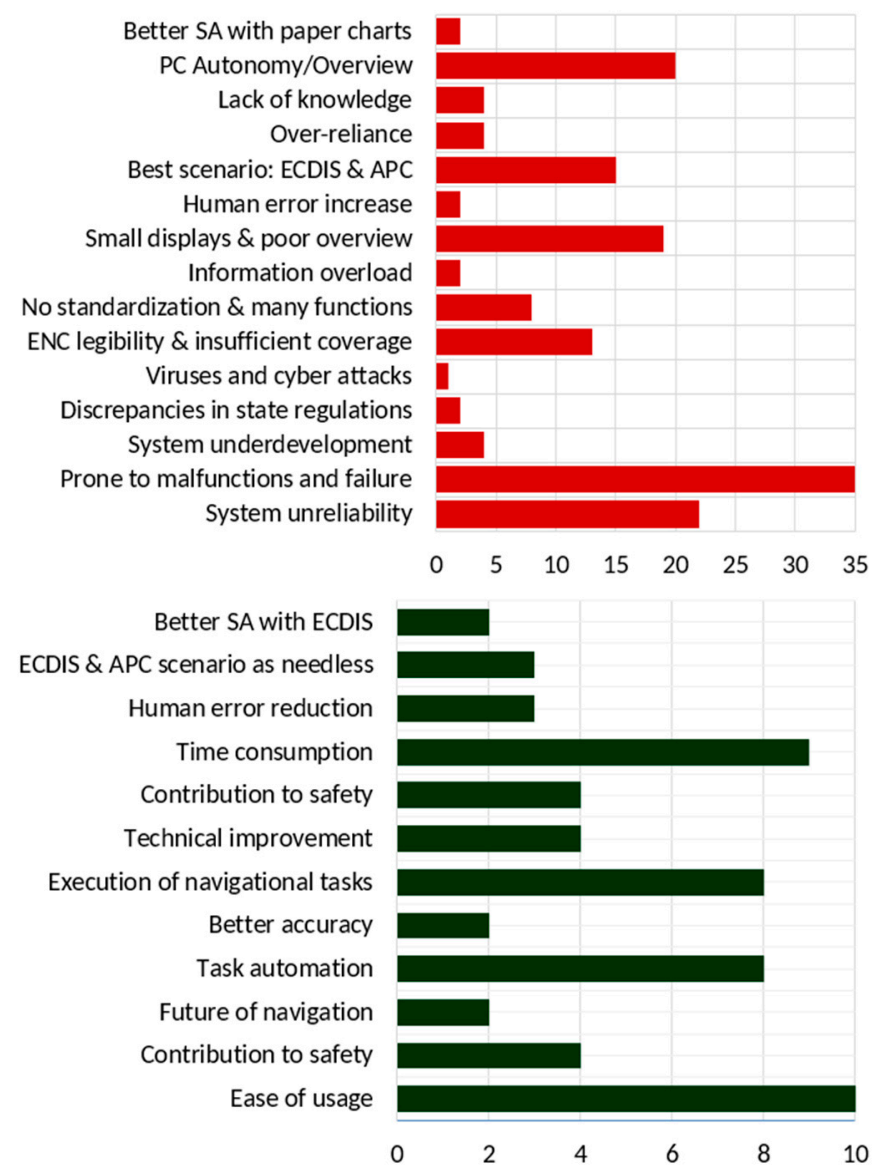

Figure 2. Counts (x-axis) of feature comments (y-axis) on advantages (lower image: system supporters) and drawbacks (upper image: traditional supporters) of ECDIS navigation compared with traditional means adopted and modified from [20].

\section{Research Methodology}

The research methodology has used two interrelated, separated parts: (i) the segment of ECDIS Experience, Handling, and Opinion (EHO) research and the (ii) Human Machine Interface (HMI) survey.

The ECDIS EHO research has started in the first years of the implementation period to improve educational processes and to develop an appropriate curriculum to increase the level of knowledge of the Officers of the Watch (OOW), being the true system end-users. One of the research tools has been an international questionnaire consisting of introductory and topic-related questions, providing feedback received from navigational ranks and, to a lesser extent, from apprentice officers and other system stakeholders.

The previous research results and findings have yielded several scientific, educational and practical contributions, reflecting, among other things, in educational process improvements [13,16,18-20,22-24]. Recognized key observations have served as an additional factor for the proposed study. While the distribution and analysis of the questionnaire ended on 1st of July 2018, the research continued further in different segments. On November 2018, the HMI survey was distributed to the international maritime professionals, containing 19 introductory and topic-related questions. Representing a continuation of the research, a dedicated online survey was distributed to the navigational ranks who have obtained the Generic ECDIS certificate at least. The concept of the ECDIS EHO survey methodology has been presented in Figure 3, with the HMI segment added as well as incorporated after the implementation period. 


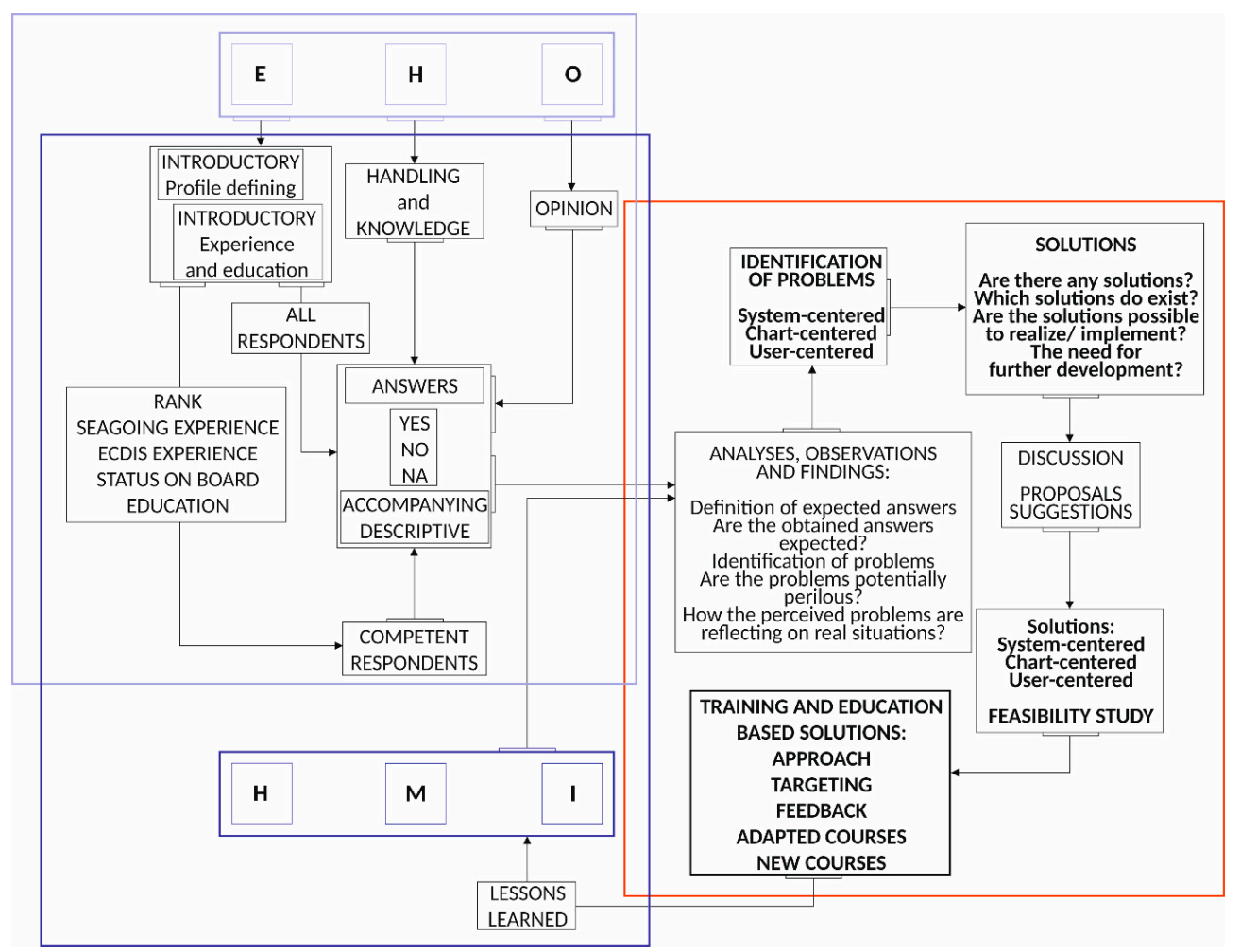

Figure 3. The concept of the ECDIS Experience, Handling, and Opinion (EHO) methodology with the Human Machine Interface (HMI) segment adapted, modified, and complemented on the basis of [5].

The subject of this research has been the opinion and the mindset of current navigational ranks, which have had the opportunity to work with both types of the navigational means. The research has focused on eligible navigational ranks: masters, staff captains, chief officers, safety officers, 1st officers navigation, second officers, and the third officers. The following introductory questions have been used in both the surveys to categorise the respondents' profiles:

- rank,

- working experience,

- $\quad$ holding the ECDIS Generic Training Certificate, and

- holding the type specific/ECDIS manufacturer-approved equipment-specific training.

The following topic-related questions from $E H O$ and $H M I$ segments/questionnaires have been analysed, with the $E H O$ part providing a possibility of accompanying comments to possible YES/NO answers:

- Do you agree with the withdrawal of paper charts from service if certain conditions are met regarding the ECDIS system, i.e., there is no further obligation to possess the same? You can explain the YES/NO answer if you want to. (abbreviated further as Q1 EHO),

- Do you think that it is still necessary to keep navigational paper charts after implementation of the mandatory ECDIS system? (abbreviated further as Q2 HMI).

At this point, the collected answers have been regrouped in the main research categories', containing introductory and topic-related questions, i.e., their responses.

Respondents have been categorized according to navigational ranks, years of sea experience, and ECDIS-related certificates' holders. Summarized results have been given for the Q1 EHO and Q2 $H M I$ questions. The EHO segment comments have been categorised and discussed in the respective section. The obtained results, analysis, and discussion have been presented as follows. 


\section{Results}

A total of 402 maritime active seafarers have taken part in the research, with the working experience ranging from one to more than 20 years.

The ECDIS EHO survey (Figure 4) has included answers from 269 respondents: 100 masters, 8 staff captains, 77 chief officers, 4 safety officers, 67 second officers, and 13 third officers. As for their active working experience, 5 categories have been defined: (i) the 6\% respondents have had less than 5 years of working experience, (ii) $14 \%$ have had 5 to 10 years of experience, (iii) $40 \%$ have had experience from 10 to 20 years, (iv) 40\% of respondents have had from 10 to 20 years of working experience, and (v) 37\% of respondents have had more than 20 years of working experience. The remaining $3 \%$ have not specified this answer.
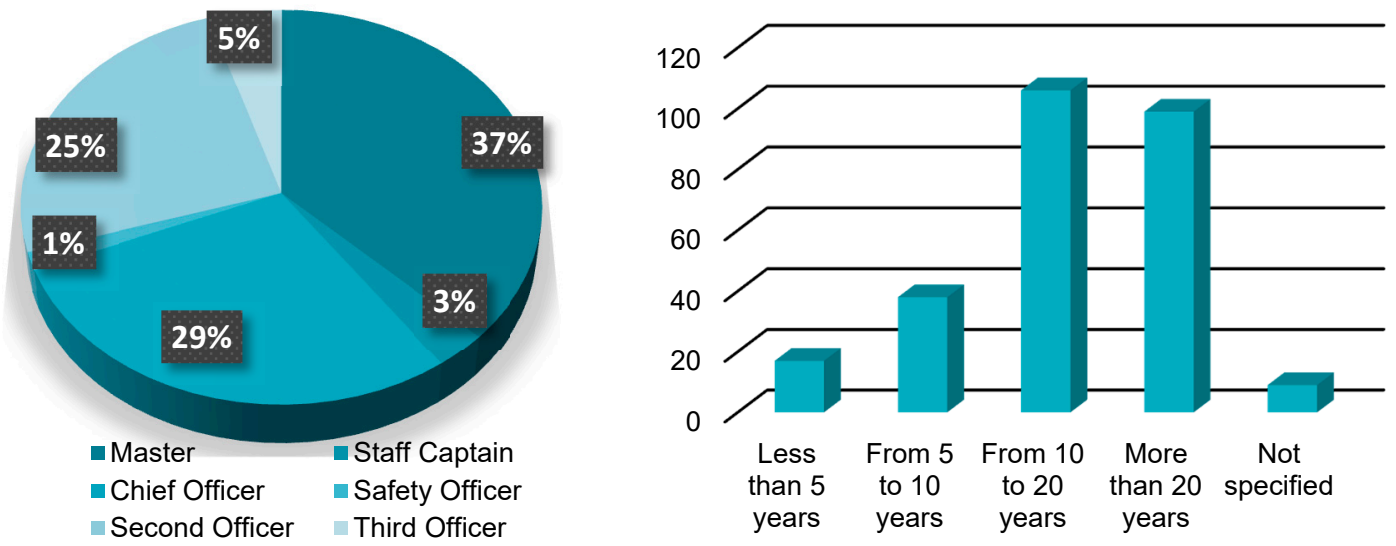

Figure 4. Navigational ranks of ECDIS EHO participants (left) and their sea experience (in years) (right). Source: Authors.

The HMI survey (Figure 5) has included answers from 133 respondents: 44 masters, 10 staff captains, 35 chief officers, 10 1st officers navigation, 23 second officers, 8 third officers, and 3 undefined respondents. Active working experience of the participants has been divided into five categories: respondents with less than five years of working experience (12\%), respondents from 5 to 10 years of working experience (27\%), respondents from 10 to 15 years of working experience (27\%), respondents from 15 to 20 years of working experience (15\%), and respondents with more than 20 years of working experience $(19 \%)$.
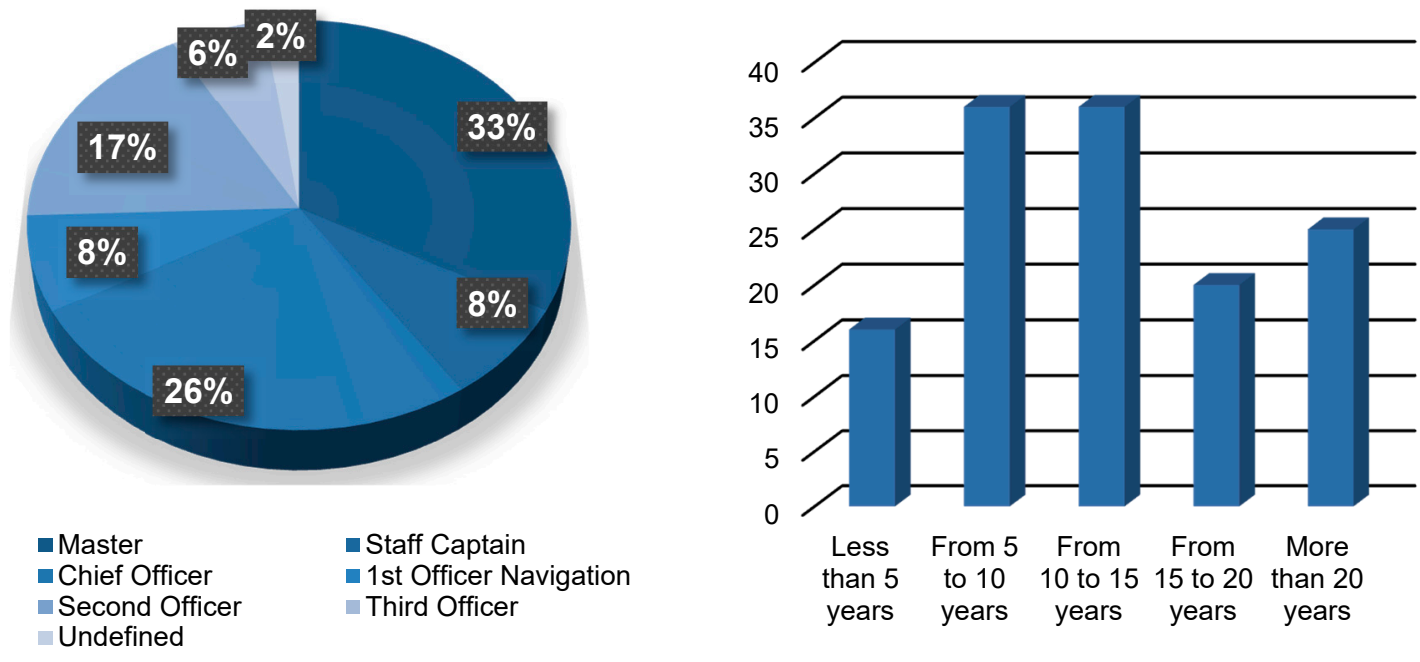

Figure 5. Navigational ranks of $H M I$ participants (left) and their sea experience (in years) (right). Source: Authors. 
During the transitional period, it has been noted that the generic ECDIS certification from the participants in the ECDIS EHO survey has increased from $61 \%$ to $100 \%$ in the HMI survey. The type-specific (familiarization) ECDIS training certification has risen from $47 \%$ in the ECDIS EHO survey to $90 \%$ in the HMI survey, as shown in Figure 6.
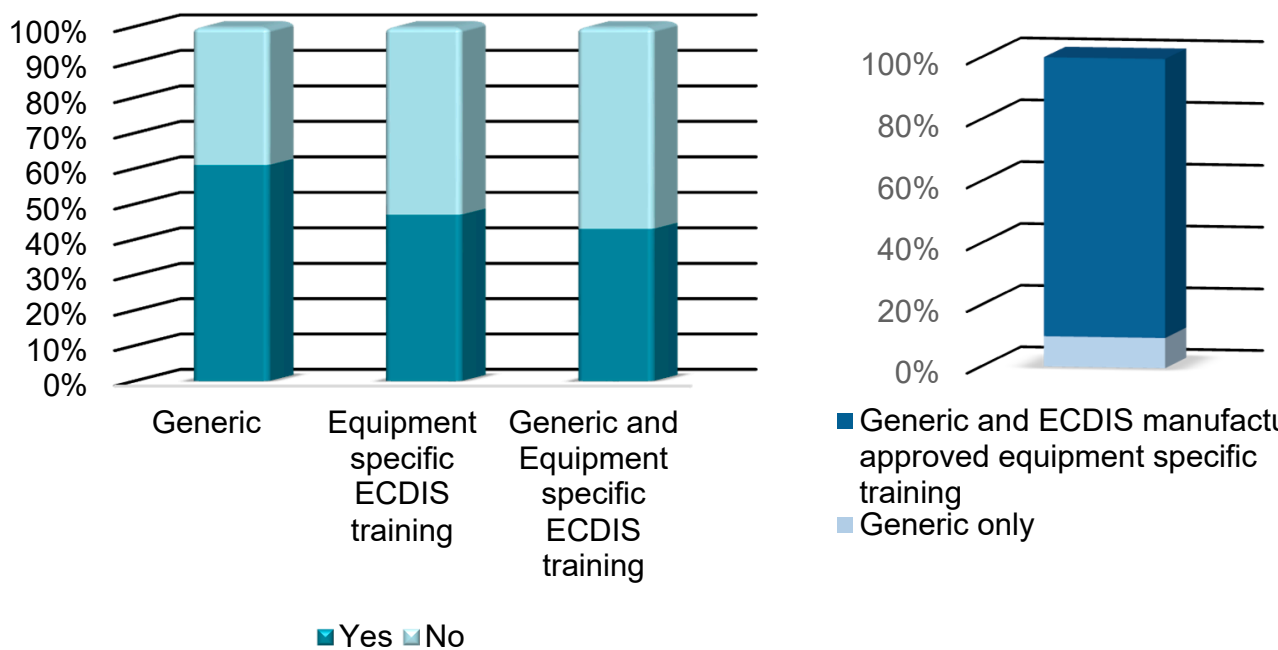

- Generic and ECDIS manufacturer approved equipment specific training

Generic only

Figure 6. Presentation of answers referring to the possession of the generic training certificate, type-specific training certificate, and both certificates according to EHO (left) and HMI survey (right) results. Source: Authors.

The ECDIS EHO participants have had an option to specify the system model on which they had attended the certification course. Transas has been the most commonly utilized system for the generic training certification, while for the type-specific training certification, SAM Electronics was the prevailing one.

The total share of answers on $(Q 1 E H O)$ and $(Q 2 H M I)$ is shown in Figure 7, together with the trend of the respondents' opinions. In the $E H O$ research, there have been a few cases where participants have not given an answer, thus making a $4 \%$ share of all responses. In general, more than half $(52 \%)$ of the respondents have agreed with the paper chart withdrawal from service if certain conditions have been met regarding the ECDIS system (ECDIS EHO). In comparison, almost $73 \%$ of the HMI survey participants have agreed to the PNC removal. There has been a positive, increasing trend for more than $20 \%$ in favour of the PNC removal after the mandatory ECDIS implementation.
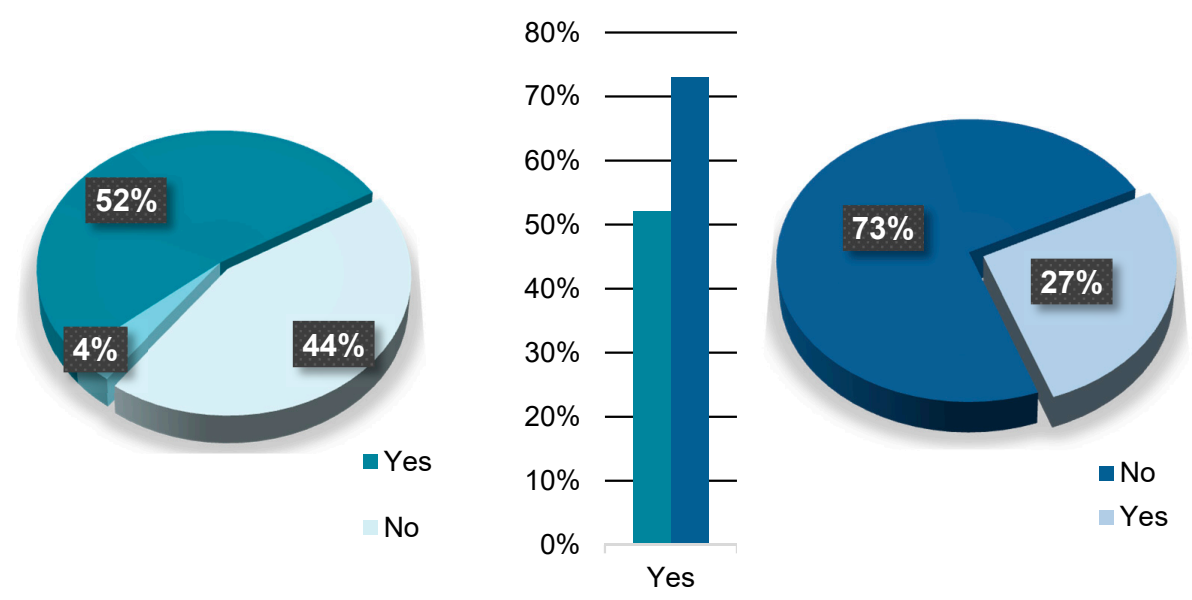

Figure 7. ECDIS EHO participants' opinions regarding Paper Navigational Chart (PNC) removal (left), the trend of affirmative PNC removal answers (centre), and HMI participants' opinions regarding the necessity of the PNCs (right). Source: Authors. 
Despite all efforts, system modernization, professional certifications, training, and hands-on experience of the participants, there has still been a considerable share of the respondents $(27 \%)$ who have favoured PNCs and traditional means of navigation and their opinions cannot be ruled out.

\section{Further Analyses and Discussion: Towards the Unwanted Chain of Errors Avoidance}

As a technical achievement, the ECDIS has been conventionally accepted as a primary navigational means, having brought many benefits to seafarers. Generally speaking, this fact has been expected. Nevertheless, it would be reasonable to elaborate on the opinions of the seafarers from both the researches who have favoured PNCs and traditional navigational means. There is a division of seafarers [30], as to whether they have developed their navigational skills before or after the electronic means have taken place globally, requiring their roles and working experience to be considered. The overall results have been subsequently analysed by years and participants' rank.

A first analysis has been made on the basis of the questionnaire submission year. The results in terms of three answering options (yes/no/no answer) have been plotted using a 100\% stacked column chart (Figure 8). This allowed comparison of the percentage of contribution for each category, showing that the most significant share on the PNC removal was in 2018, equal to more than $65 \%$.

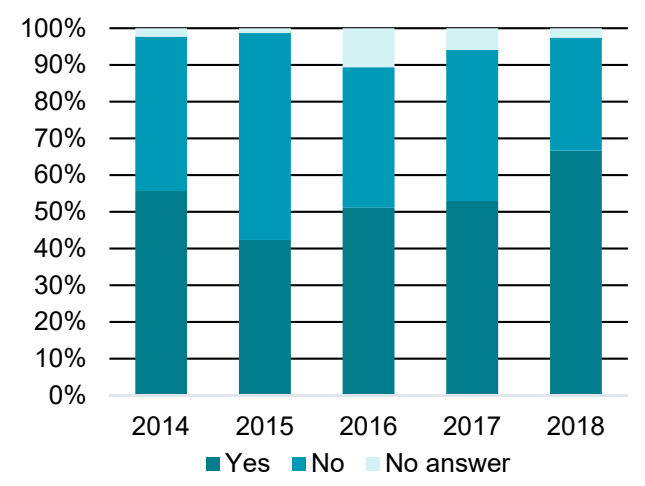

\begin{tabular}{|c|c|c|c|c|c|}
\hline Year & 2014 & 2015 & 2016 & 2017 & 2018 \\
\hline Yes & 49 & 33 & 24 & 9 & 26 \\
\hline No & 37 & 44 & 18 & 7 & 12 \\
\hline $\mathrm{Na}$ * & 2 & 1 & 5 & 1 & 1 \\
\hline \multicolumn{6}{|c|}{ * No answer } \\
\hline
\end{tabular}

Figure 8. ECDIS EHO survey participants' opinions regarding PNC removal divided by years. Source: Authors.

The second analysis regarded both the navigational rank and the questionnaire submission year (Table 1 and Figure 9, respectively).

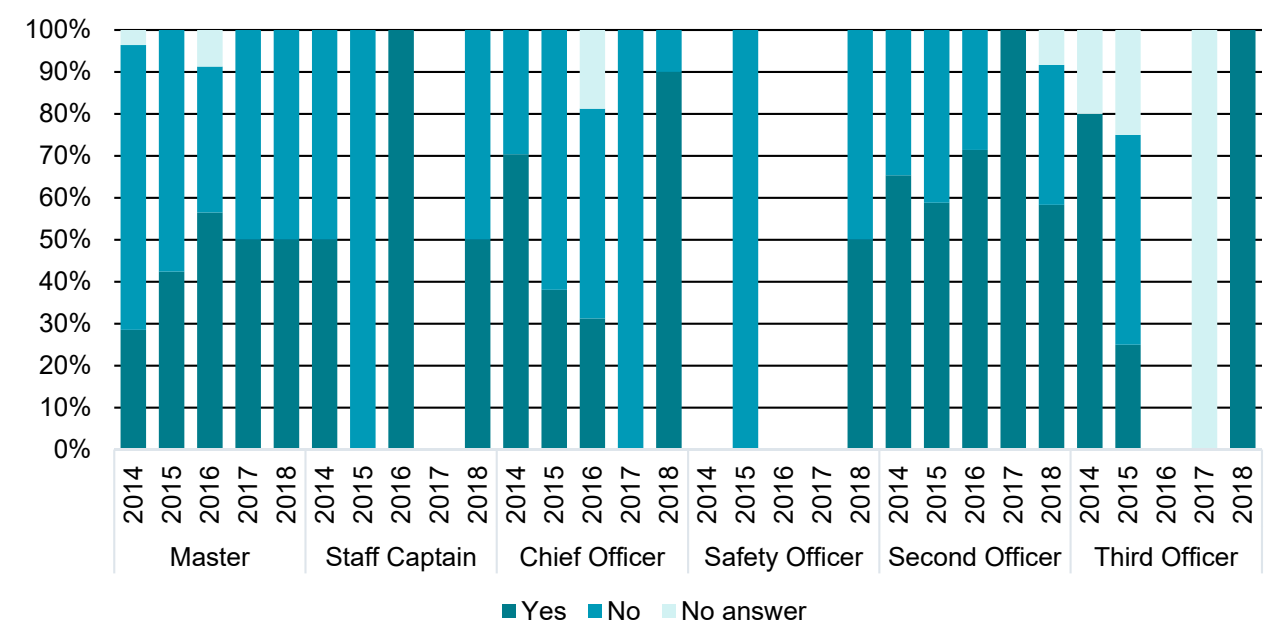

Figure 9. ECDIS EHO participants' opinions regarding PNC removal divided by years and rank (Q1: Do you agree with the fact of the withdrawal of the paper charts from the service if certain conditions are met regarding the ECDIS system, i.e., there is no further obligation to possess the same?) Source: Authors. 
Table 1. ECDIS EHO participants' opinions regarding PNC removal divided by years and rank.

\begin{tabular}{|c|c|c|c|c|c|c|c|c|c|c|}
\hline Year & 2014 & 2015 & 2016 & 2017 & 2018 & 2014 & 2015 & 2016 & 2017 & 2018 \\
\hline Yes & 8 & 14 & 13 & 4 & 4 & 1 & 0 & 1 & 0 & 2 \\
\hline No & 19 & 19 & 8 & 4 & 4 & 1 & 1 & 0 & 0 & 2 \\
\hline No answer & 1 & 0 & 2 & 0 & 0 & 0 & 0 & 0 & 0 & 0 \\
\hline Rank & \multicolumn{5}{|c|}{ Master } & \multicolumn{5}{|c|}{ Staff Captain } \\
\hline Year & 2014 & 2015 & 2016 & 2017 & 2018 & 2014 & 2015 & 2016 & 2017 & 2018 \\
\hline Yes & 19 & 8 & 5 & 0 & 9 & 0 & 0 & 0 & 0 & 1 \\
\hline No & 8 & 13 & 8 & 3 & 1 & 0 & 2 & 0 & 0 & 1 \\
\hline No answer & 0 & 0 & 3 & 0 & 0 & 0 & 0 & 0 & 0 & 0 \\
\hline Rank & \multicolumn{5}{|c|}{ Chief Officer } & \multicolumn{5}{|c|}{ Safety Officer } \\
\hline Year & 2014 & 2015 & 2016 & 2017 & 2018 & 2014 & 2015 & 2016 & 2017 & 2018 \\
\hline Yes & 17 & 10 & 5 & 5 & 7 & 4 & 1 & 0 & 0 & 3 \\
\hline No & 9 & 7 & 2 & 0 & 4 & 0 & 2 & 0 & 0 & 0 \\
\hline No answer & 0 & 0 & 0 & 0 & 1 & 1 & 1 & 0 & 1 & 0 \\
\hline Rank & \multicolumn{5}{|c|}{ Second Officer } & \multicolumn{5}{|c|}{ Third Officer } \\
\hline
\end{tabular}

When comparing years 2014 and 2018, an even opinion or slight increase among all navigational ranks, with an exception of second officers, has been noted regarding the favouring of electronic navigation means, as opposed to traditional navigation. When analysing the first six months of the year 2018 (EHO) and the time frame before mandatory system implementation, there were still $50 \%$ of the masters, who have not agreed with the PNC removal. Staff captains and safety officers were equally divided (50\%). A $90 \%$ of the chief officers and a significant share of the second officers $(42 \%)$ did not agree with the PNCs withdrawal from the service. Although represented in a relatively small share, the results indicated that $100 \%$ of the third officers would like to withdraw the PNCs.

The general percentage of answers on Q2 HMI regarding the navigational rank is shown in Figure 10. The relative share of two possible answers (yes/no) has been provided by each participant's rank. Approximately $60 \%$ of masters, staff captains, and third officers would like to withdraw PNCs from the service after the mandatory system implementation. The majority of the second officers $(78 \%)$ and chief officers $(86 \%)$, as well as all of the 1 st officers navigation share the same opinion. The exception have been unspecified participants ( $2 \%)$.

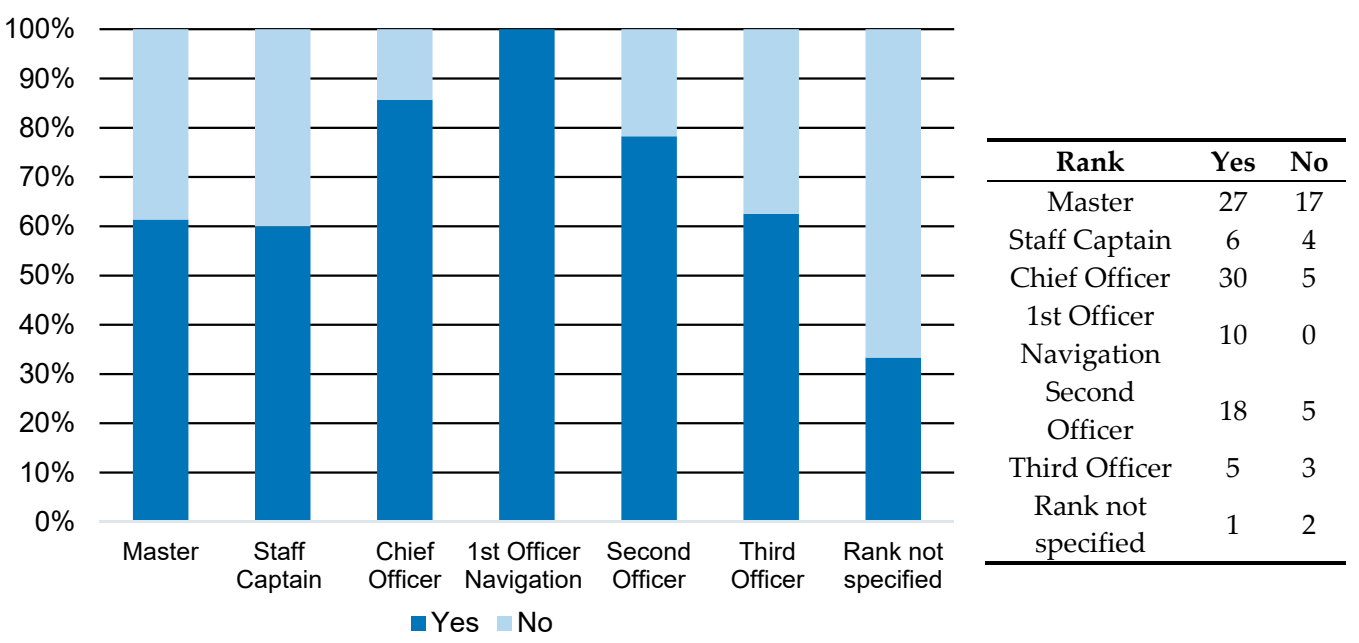

Figure 10. HMI survey participants' opinions regarding PNC removal (Q2: Do you think that it is still necessary to keep navigational paper charts after implementation of the mandatory ECDIS system?). Source: Authors. 
Masters and staff captains have favoured the PNC removal for an additional 10\%, while there has been approximately $20 \%$ of the increase of the second officers who share the same opinions (in 2018, as derived from both surveys). There has also been a $4 \%$ decrease in opinions of the chief officers (from $90 \%$ to $86 \%$ ), and $38 \%$ of the third officers who have favoured the PNC removal after the mandatory system implementation. The total share of the answers from participants who have supported the PNC removal decreased from $100 \%$ to $62 \%$. Since the individual results have not been totally uniform, more specific research should be conducted, providing a larger, and therefore, more representative samples of participants' categories. So far and it is, generally speaking, logical, the senior ranks have been mostly more reluctant to discontinuation of the PNCs usage, as opposed to junior officers. The latter have been in total consensus about the PNCs' complete removal from the service. Another consequential and perhaps underrated question has emerged or, rather to say, it has been confirmed: To what extent will the traditional supporters ignore the usage and the features of the system as a result of their standpoints regarding the non-acceptance, or even resistance to the means? Although seemingly negligible, this issue refers to the desired synergy between traditional and system supporters, i.e., their ability for joint and successful achievement of safe navigation.

Several potential issues and uncertainties can be identified on the basis of these results. The categorized issues have been shown in Figure 11. In their nature, they can be divided in two major groups: (i) system and data problems (grey coloured rectangles and orange arrows) and (ii) operational (navigator's) issues (blue coloured rectangles and orange arrows). Both can individually lead to potential precarious and difficult situations (red coloured rectangle), e.g., overreliance as a navigator's problem, or the ENC information quality as a data problem leading to difficulties or risks in system handling and the execution of navigation tasks.

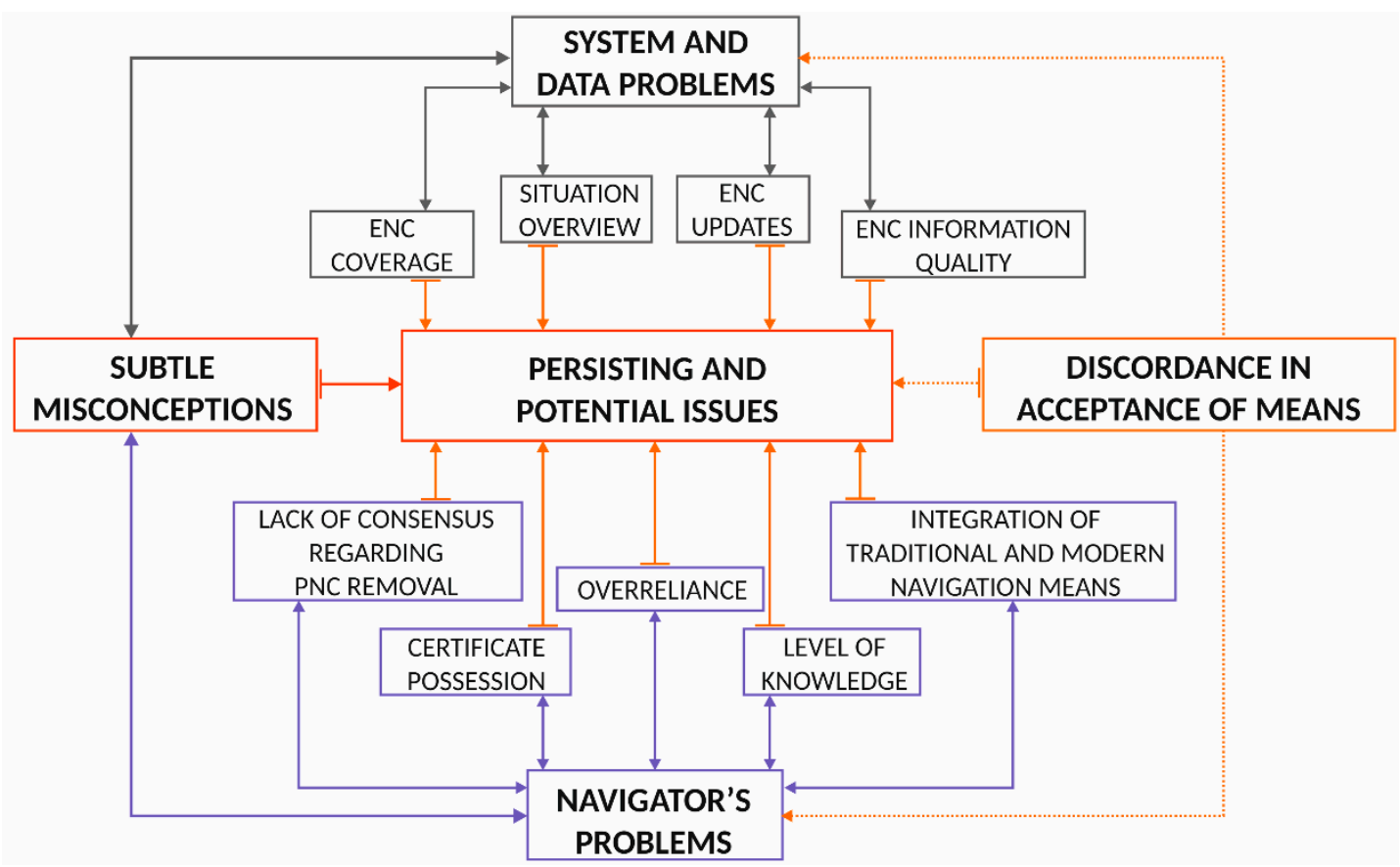

Figure 11. The model of ENC cause-and-effect chain of adverse events. Source: Authors.

A combination of (i) (grey coloured arrows) and (ii) (blue coloured arrows) has been pointed out (red arrowed colour) as a most unwanted scenario, i.e., an operator with a low level of knowledge experiencing a system problem. As for discrepancies in the system acceptance, they could lead to intentional non-usage of the system and its features, nevertheless its role. This, unwanted chain of errors leading to potential hazards has been found, especially in this instant of time, to pose a serious threat to the navigation venture. 
Subsequent findings can be elaborated as follows:

- the trend of digital means' acceptance has increased, as expected,

- even though the system has been generally accepted among the end-users, there have still been specific issues which the system users have been pointing out, with similar key points confirmed by the respective organisations,

- like any other technical instrument, the system is prone to failures, what has been expectedly recognised by the end-users,

- the system users have identified the handling-independent problem of the ENC coverage,

- the ENC updates are dependent on satellite communication systems and internet availability,

- the quality of the displayed ENC information differs, depending on their depth accuracy level,

- in certain instances, the PNCs can offer a better overview of some navigable waters (coastal navigation, port approaches) due to their size,

- besides handling the system and familiarizing with, it is necessary to obtain, gain, and maintain a certain level of knowledge and skills to operate with the system properly,

- a problem of overreliance can emerge in terms of exaggerated confidence in the system,

- there are still OOWs without system-approved equipment specific training.

- opinions regarding PNC removal from the service widely differs between research participants,

- a recognized and justified need to incorporate traditional navigational means with modern navigational means to contribute to the safety of navigation has appeared.

Modern technology has speeded up the process of navigation planning, and facilitated easier monitoring of the vessel's movement and navigation. Even though most of the respondents agreed about the PNC removal, it would be prudent not to disregard suggestions from traditional navigation advocates. According to the presented analyses, a minimum set of PNCs should be kept on board as a back-up arrangement in a case of emergency as a worst-case scenario, especially when taking into consideration the ECDIS EHO participants' legitimate comments and concerns about issues on the system. Those have been addressed not only as system crash downs, screen freeze, and issues related to system and ENC updates but also as the announcements of certain hydrographic offices regarding the PNCs removal from the service [26]. There has been more than one-fourth of the respondents-after the transitional period completion-who have still been favouring the PNCs. As for navigational charts, the potential problem is standing in front of the considerable number of modern seafarers who have still been stranded in the traditional navigation era.

\section{Conclusions}

Digital navigation is replacing traditional means. Paperless navigation relies on present and future maritime navigational trends, with integrated navigational systems, e-navigation, and coordinating cloud data exchanges between vessels and the shore as most common examples.

The research carried out in this paper has focused on the opinions and arguments of eligible officers as the central stakeholders in the process of the maritime navigation, elaborating their level of acceptance of new navigational means. This research aimed at addressing potential problems arising from the transition to electronic charts to improve the safety of navigation. The participants' answers have been collected and analysed during and after the transitional period, considering their response through the survey periods and their current engagement with the ECDIS system.

The results have pointed out measurable differences in opinions on a particular navigational rank and trends of opinions through five consecutive years. As seen from the navigational ranks' standpoints, even though there has been a positive, increasing, and finally expected trend regarding the PNC removal from the service, except for the chief officers, there have still been more than one-fourth of the research participants who have, in one-way, been favouring the PNCs and traditional navigation means. Senior navigational ranks and overall commanding officers have still been reasonably reserved towards new technologies. The reasons can be found in existing system- and chart-related issues 
and insufficient trust in electronic equipment. Here, traditional equipment has been considered as an irreplaceable support. Apart from technical issues, the updating level of knowledge is essential, adapted to the particular rank and its actual engagement with the system, rather than relying on formal, prevalent courses. The research has indirectly confirmed the unwanted possible consequences of overreliance which could lead to the lack of situational awareness.

The research results brought up the complex matter referring to the particular approach of navigational ranks of different standpoints and, consequently, their mutual relationship aimed to provide a safe navigation. The discordance in accepting of navigational means could have a negative impact on conducting tasks in the ECDIS navigation and the synergy of the bridge team. Further, the integration of traditional and modern means appears to contribute to the safety of navigation.

The research findings have indicated a need for further analysis of the answers given by particular respondents' groups, especially the ranks which have been less represented in the research, e.g., the third officers. A further continuation of the research has been planned in order to engage as many navigational ranks as possible, in order to maintain and improve this feedback mechanism.

In pace of time and of the new generations of seafarers, it is to expect that they will categorically accept the modern navigation means. However, it has been evident that the PNCs cannot be entirely discarded. Even though the introduction of the ECDIS has not necessarily implied complete PNCs withdrawal, it can be assumed that it will happen. With the rise of new chart-creation technologies, it can be expected that the electronic charts and their appropriate accuracy will further improve. Nevertheless, it seems that the time has not yet come.

Author Contributions: Conceptualization, D.B. and M.C.; methodology, D.B., M.C., and S.Ž.; validation, D.B., S.Ž., B.S., and M.C.; formal analysis, D.B. and S.Ž.; investigation, M.C. and D.B.; resources, S.Z., D.B., and B.S.; data curation, M.C.; writing—original draft preparation, M.C.; writing—review and editing, M.C., D.B., S.Ž., and B.S.; visualization, M.C. and D.B.; supervision, D.B.; project administration, D.B. and B.S.; funding acquisition, B.S. All authors have read and agreed to the published version of the manuscript.

Funding: This research was financially supported, and the APC was funded by the University of Rijeka research project Cyber Security of Maritime ICT-Based Systems (grant number: uniri-tehnic-18-68).

Acknowledgments: This study has been supported by the University of Rijeka under the Faculty of Maritime Studies project ECDIS EHO and by the University of Rijeka research project Cyber Security of Maritime ICT-Based Systems (uniri-tehnic-18-68). The authors are grateful to all the navigational ranks, officers of the navigational watch, and other ECDIS stakeholders for their time and willingness to fulfil the surveys and discussions. The authors believe that their answers and opinions have an immense significance for the appropriateness of the research deliverables.

Conflicts of Interest: The authors declare no conflict of interest.

\section{References}

1. International Maritime Organization, IMO. International Convention for the Safety of Life at Sea, 1974 as Amended; IMO: London, UK, 2014.

2. International Hydrographic Organization (IHO). Latest IHO Standards that Apply to ECDIS Equipment and Data. 2020. Available online: https://iho.int/en/standards-in-force (accessed on 24 April 2020).

3. International Maritime Organization, IMO. Performance Standards for Electronic Chart Display and Information Systems (ECDIS); Resolution A.817 (19); IMO: London, UK, 1995.

4. International Maritime Organization, IMO. Adoption of New and Amended Performance Standards; Resolution MSC.64(67); IMO: London, UK, 1996.

5. International Maritime Organization, IMO. Adoption of the Revised Performance Standards for Electronic Chart Display and Information Systems (ECDIS); Resolution MSC.232(82); IMO: London, UK, 2006.

6. International Hydrographic Organization, IHO. IHO Transfer Standard for Digital Hydrographic Data; As Supplemented, Version 3.1; IHO: Monaco, 2014.

7. International Hydrographic Organization, IHO. S-52: Specifications Chart Content and Display Aspects of ECDIS; Version 6.1; IHO: Monaco, 2015.

8. International Hydrographic Organization, IHO. IHO Data Protection Scheme; Version 1.2; IHO: Monaco, 2015. 
9. International Hydrographic Organization, IHO. Information on IHO standards related to ENC and ECDIS; Version 2.1; IHO: Monaco, 2020.

10. Weintrit, A. International recent issues about ECDIS, E-navigation and safety at sea: Introduction. In International Recent Issues about ECDIS, E-Navigation and Safety at Sea; Weintrit, A., Ed.; Taylor \& Francis Group Ltd.: Boca Raton, FL, USA, 2011; pp. 9-12.

11. Turna, İ; Öztürk, B.O. A causative analysis on ECDIS-related grounding accidents. Ships Offshore Struc. 2019, 15, 792-803. [CrossRef]

12. Marine Accident Investigation Branch, MAIB. Available online: https://www.gov.uk/government/ organisations/marine-accident-investigation-branch (accessed on 15 September 2020).

13. Brčić, D.; Kos, S.; Žuškin, S. Partial structural analysis of the ECDIS EHO research: The handling part. In Proceedings of the 24th International Symposium on Electronics in Transport, Ljubljana, Slovenia, 29-30 March 2016; pp. 80-87.

14. International Hydrographic Organization, IHO. IHO Report on the Results of the ECDIS Survey Conducted by BIMCO and Denmark; IHO: Monaco, 2014.

15. Weintrit, A.; Stawicki, K. Operational requirements for Electronic Chart Display and Information Systems (ECDIS). Risk of overreliance on ECDIS. Transp. Probl. 2008, 3, 67-74.

16. Brčić, D.; Žuškin, S.; Barić, M. Observations on ECDIS education and training. In Proceedings of the 12th International Conference on Marine Navigation and Safety of Sea Transportation, Gdynia, Poland, 21-23 June 2017; pp. 29-36.

17. Cole, J.S.; Asyali, E. Role of ECDIS training on improving situational awareness. In Proceedings of the 19th IAMU AGA Conference (IAMU 19), Barcelona, Spain, 17-19 August 2018; Grifoll, M., Martínez de Osés, F.X., Castells, M., Martin, A., Eds.; Universitat Politecnica de Catalunia/International Center for Numerical Methods in Engineering: Barcelona, Spain, 2018; pp. 165-172.

18. Žuškin, S.; Brčić, D.; Šabalja, Đ. A contribution to improving the standards of ECDIS training. Pomorstvo 2013, 27, 131-148.

19. Brčić, D.; Žuškin, S. Towards paperless vessels: A master's perspective. J. Marit. Transp. Sci. 2019, 55, 183-199. [CrossRef]

20. Brčić, D.; Žuškin, S.; Valčić, S.; Rudan, I. ECDIS transitional period completion: Analyses, observations and findings. WMU J. Marit. Aff. 2019, 18, 359-377. [CrossRef]

21. Rutkowski, G. ECDIS Limitations, data reliability, alarm management and safety settings recommended for passage planning and route monitoring on VLCC tankers. TransNav Int. J. Mar. Navig. Saf. Sea Transp. 2018, 12, 483-490. [CrossRef]

22. Brčić, D.; Kos, S.; Žuškin, S. Navigation with ECDIS: Choosing the proper secondary positioning source. TransNav Int. J. Mar. Navig. Saf. Sea Transp. 2015, 9, 317-326. [CrossRef]

23. Žuškin, S.; Brčić, D.; Kos, S. Partial structural analysis of the ECDIS EHO research: The safety contour. In Proceedings of the 7th International Conference on Maritime Transport, Barcelona, Spain, 27-29 June 2016; Martinez de Oses, F.X., Castells Sanabra, M., Eds.; Universitat Politecnica De Catalunya-UPC: Barcelona, Spain, 2016; pp. 246-262.

24. Car, M.; Vujičić, S.; Žuškin, S.; Brčić, D. Human machine interface: Interaction of OOWs with the ECDIS system. In Proceedings of the 1st International Conference of Maritime Science \& Technology (NAŠE MORE 2019), Dubrovnik, Croatia, 17-18 August 2019; Koboević, Ž., Ed.; pp. 74-86.

25. International Hydrographic Organization, IHO. The Future of the Paper Nautical Charts; Preliminary Report; IHO: Monaco, 2019.

26. National Oceanic and Atmospheric Administration (NOAA). Sunsetting Traditional NOAA Paper Charts. End of Paper and Raster Nautical Chart Production Introduction of NOAA Custom Charts; National Oceanic and Atmospheric Administration: Washington, DC, USA. Available online: https://www.noaa.gov/ (accessed on 29 January 2020).

27. Kristić, M.; Žuškin, S.; Brčić, D.; Valčić, S. Zone of confidence impact on cross track limit determination in ECDIS passage planning. J. Mar. Sci. Eng. 2020, 8, 566. [CrossRef]

28. International Hydrographic Organization. Mariners Guide to Accuracy of Electronic Navigational Charts (ENC); Version 1.0.0; IHO: Monaco, 2020. 
29. Li, Z.; Jonas, W.; Ringsberg, J.W.; Rita, F. A voyage planning tool for ships sailing between Europe and Asia via the Arctic. Ships Offshore Struc. 2020. [CrossRef]

30. International Maritime Organization, IMO. Model Course 1.27, Operational Use of Electronic Chart Display and Information System; IMO: London, UK, 2010.

Publisher's Note: MDPI stays neutral with regard to jurisdictional claims in published maps and institutional affiliations.

(C) 2020 by the authors. Licensee MDPI, Basel, Switzerland. This article is an open access article distributed under the terms and conditions of the Creative Commons Attribution (CC BY) license (http://creativecommons.org/licenses/by/4.0/). 